\title{
History of insulin treatment of pediatric patients with diabetes in Korea
}

\author{
Jae Hyun Kim ${ }^{1,2}$, \\ Choong Ho Shin ${ }^{1,3}$, \\ Sei Won Yang ${ }^{4}$
}

'Department of Pediatrics, Seoul National University College of Medicine, Seoul, Korea

${ }^{2}$ Department of Pediatrics, Seoul National University Bundang Hospital, Seongnam, Korea

${ }^{3}$ Department of Pediatrics, Seoul National University Children's Hospital, Seoul, Korea

${ }^{4}$ Korea International Cooperation Agency, Seoul, Korea
Received: 15 December, 2021 Accepted: 19 December, 2021

Address for correspondence: Choong Ho Shin

Department of Pediatrics, Seoul National University Children's Hospital, 101 Daehak-ro, Jongnogu, Seoul 03080, Korea

Email: chshinpd@snu.ac.kr https://orcid.org/0000-0002-98131134
The year 2021 is the centennial of insulin discovery. The discovery of insulin changes diabetes mellitus from a death sentence to a manageable disease. It became a historical turning point in the lives of people with diabetes. Since the first use of insulin in a patient in 1922, insulin and its analogs have been remarkable in saving the lives of people with diabetes. As insulin began to be used as a drug, it was introduced to, and used in Korea until now. This review briefly summarizes the history of insulin treatment in Korean children and adolescents with diabetes.

Keywords: Insulin, History, Korea, Child, Adolescents

\section{Highlights}

The year 2021 is the centennial of insulin discovery. As insulin and insulin analogs began to be used as a drug, they were introduced to, and used in Korea until now. New types of smart insulin and more advanced devices developed in the future can make diabetes an easier-tomanage disease.

\section{Introduction}

The year 2021 is the centennial of the discovery of insulin (Fig. 1). The first description of diabetes mellitus (DM) was documented on papyrus scrolls of ancient Egypt in 1500 B.C. However, DM treatment began with the discovery of insulin. In 1921, Frederick Banting and Charles Best of the University of Toronto successfully extracted insulin from the pancreas of a dog. ${ }^{1)}$ Since insulin was first administered to Leonard Thompson, a patient with juvenile DM in November 1922, insulin has become the cornerstone of treatment for DM. Frederick Banting and John Macleod were jointly awarded the Nobel Prize in 1923 for the discovery of insulin. Insulin changes DM from a death sentence to a manageable disease. ${ }^{2)}$

The incidence of DM in children and adolescents is low in Korea compared to that in Western countries. However, recent studies have shown that the incidence of DM is increasing, similar to that in other countries. ${ }^{3)}$ In metropolitan Seoul, the incidence of type 1 diabetes (T1D) was first reported as 0.5/100,000 among boys and 0.6 per 100,000 in girls aged $<15$ years in 1985-1986. ${ }^{4)}$ The most recent study revealed that the incidence of T1D increased to 4.89 and 4.67 per 100,000 , respectively, for boys and girls aged $<15$ years in 2016 , which indicates an approximately 9 -fold increase over 30 years. ${ }^{5)}$ Along with the increasing number of pediatric patients, the development of various insulin analogs and the advancement of diabetes technology have increased social interest.

In this article, the history of insulin treatment in Korean pediatric patients with diabetes is reviewed for the centennial discovery of insulin. 


\section{Early reports of pediatric patients with diabetes}

In 1923, a news article reporting the Nobel Prize Awarded for the discovery of insulin was released in Chosun Ilbo, which is thought to be the first documentation of insulin in Korea. ${ }^{6}$ Since DM was introduced as a differential diagnosis of enuresis in Chosun Ilbo in 1924, ${ }^{7)}$ articles on pediatric DM were intermittently published in newspapers.

The first case report on pediatric DM was published in the Journal of Korean Pediatric Society in 1959.8) A 6-monthold male patient was admitted to Yonsei University Severance Hospital because of turbid urine and delayed weight gain. On admission, he had a fasting glucose level of $467 \mathrm{mg} / \mathrm{dL}$ and ketosis. After admission, regular insulin (RI) was administered subcutaneously 4-5 times per day, and once-daily neutral protamine Hagedorn (NPH) insulin was injected. Upon discharge, he was injected with 10 units of NPH per day. Although it was not certain whether this patient had neonatal diabetes due to a monogenic cause or T1D, he was the first published case of pediatric diabetes in Korea.

The second case, reported in Dong-a Ilbo on December 18, 1962, was a 10-year-old girl with polyphagia, polydipsia, and polyuria. After the diagnosis of DM, the patient was treated with RI. ${ }^{9)}$

In 1966, the first case of diabetic ketoacidosis (DKA) with coma was published in the Journal of Korean Pediatric Society. ${ }^{10)}$ This 13-year-old male patient was diagnosed with DM in 1953, which was the earliest diagnosis of DM in Korea. The patient had severe DKA at admission to Seoul National University Hospital with a total $\mathrm{CO}_{2}$ of $6.1 \mathrm{mEq} / \mathrm{L}$ and showed Kussmaul respiration and comatose mentality. For the treatment of DKA, subcutaneous and intravenous injections of RI were administered, followed by subcutaneous RI injection every 4 $\mathrm{h}$ along with fluid therapy. After 2 hours of DKA treatment, his mental state started to improve, and after 24 hours, his general condition improved and he began to eat. After acute management of DKA, NPH, and RI were administered once per day for glycemic control. Although there are slight differences between past and current DKA management, insulin and fluid therapy remain the cornerstone of management of DKA.

After these initial case reports, several more cases were reported in academic journals. ${ }^{11-15)}$

\section{Changes in insulin treatment among pediatric patients with diabetes}

Formal records on the first use of insulin in children and adolescents with DM are not available. However, several articles in newspapers and journal articles by Japanese researchers indicated insulin use during the Japanese colonial period. ${ }^{16)}$ At that time in Korea, insulin was imported from abroad, most of which was short-acting RI of animal origin. Insulin use in the past has been well documented in other literature.

As seen in previous studies on diabetes in children and
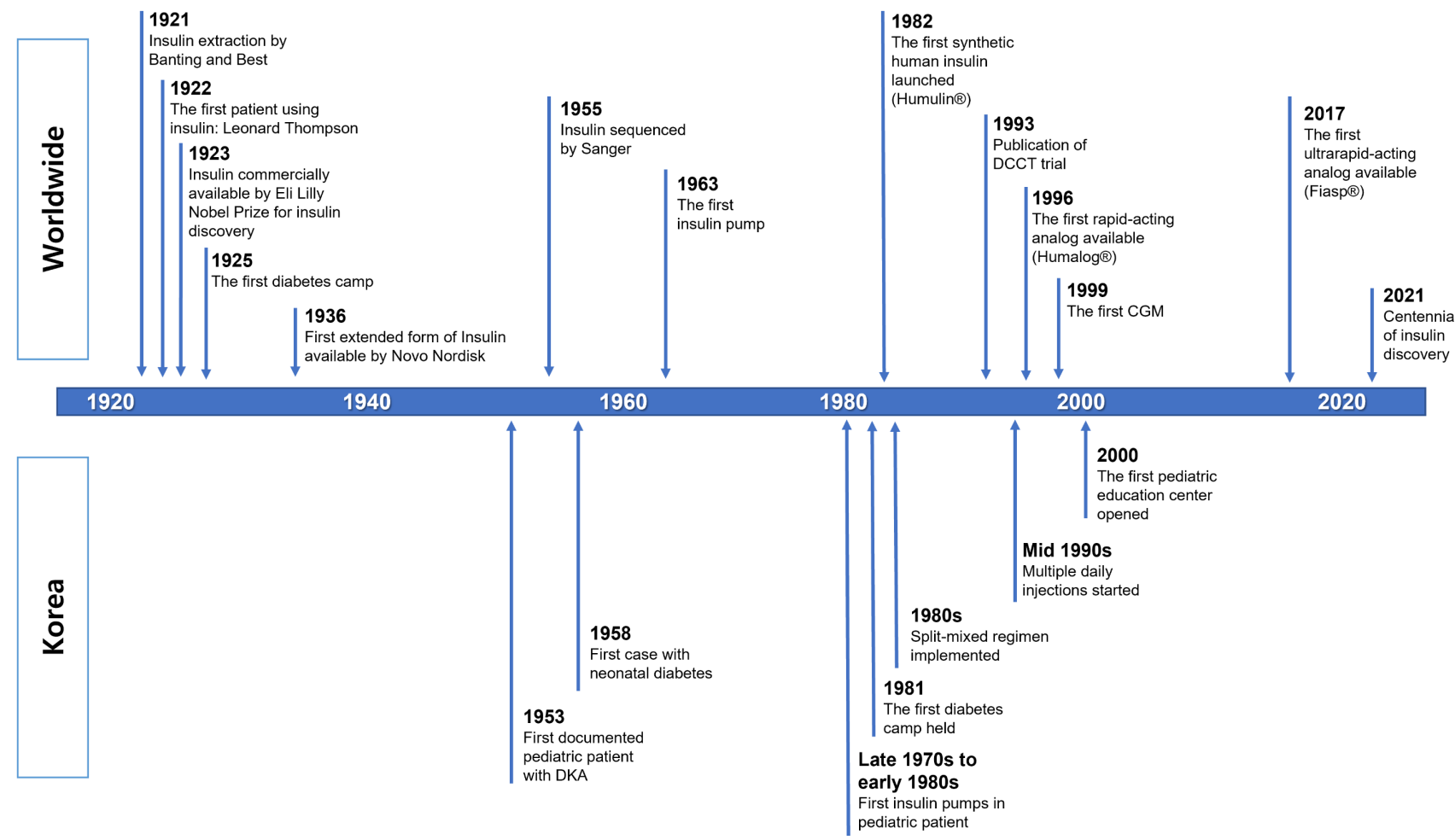

Fig. 1. Timeline of notable events associated with insulin treatment worldwide and in Korea. DCCT, Diabetes Control and Complications Trial; CGM, continuous glucose monitoring; DKA, diabetic ketoacidosis. 
adolescents in Korea, NPH and RI were used as treatments for diabetes in children and adolescents in the 1950s (Fig. 1). Until the 1980s, it was common to treat patients using animalderived RI and NPH. In situations such as DKA at diagnosis, RI was administered intravenously or subcutaneously. After the patient's condition was stabilized, glycemic control was managed by administering NPH and/or RI once daily, depending on the patient.

In a review article published in 1959, when administering more than 20 units of RI per day for adults, it was recommended to divide it into 3 doses. To reduce this inconvenience, the use of long-acting insulin such as NPH and protamine zinc insulin was recommended. ${ }^{17)}$ In addition, side effects including hypoglycemia or allergic reactions, such as anaphylaxis (especially with protamine zinc insulin), were reported. In Korea, there was a case report of a pediatric patient with DM with hypoglycemic seizures caused by insulin overdose, which resulted in brain damage. ${ }^{13)}$ However, there have been no reports of allergic reactions in children and adolescents in the Korean literature.

In a review article on pediatric diabetes published in 1968 , $10 \%$ of pediatric patients required only NPH or Lente insulin, $40 \%$ required administration of a mixture of NPH or Lente with RI once in the morning, and 50\% required the administration of a mixture of NPH or Lente with RI once in the morning and a small amount of NPH or Lente before dinner or at bedtime. ${ }^{18)}$

A mixed-split regimen, administered a mixture of NPH and RI twice a day in children and adolescents with DM, first appeared in an article published in 1983. ${ }^{19)}$ This method more closely simulates physiological insulin secretion than the conventional administration of NPH and RI once a day. According to the literature, NPH and RI were administered in the morning and evening to control blood glucose levels in patients diagnosed in 1979 and 1983. Interestingly, the terminology of 'insulindependent diabetes mellitus' first appeared in this article.
From the mid-1980s, glucometers for self-monitoring of blood glucose were distributed and their widespread use began. Previously, it had been common to measure glucose in urine, but the use of personal glucometers provided a new turning point for diabetes management.

Since the late 1980s, the mixed-split regimen has been increasingly used. Moreover, from the early 1990s, a regimen with 3 injections per day, which administers NPH and RI in the morning, RI before dinner, and NPH before bedtime, was introduced for some patients. After the results of the Diabetes Control and Complications Trial (DCCT) were published in 1993, multiple daily injections (MDI) were attempted with NPH and RI in Korea after the mid-1990s.

Insulin lispro (Humalog, Eli Lilly, Indianapolis, IN, USA), a rapid-acting insulin analog created using recombinant DNA technology, was released in 1996, imported into Korea in 1998, and used in children and adolescents beginning around the year 2000. In addition, as insulin glargine (Lantus, Sanofi, Paris, France) was developed and imported in 2005, a more modern and physiologically similar MDI using an insulin analog was used, even in children and adolescents. Since then, various types of rapid-acting and long-acting insulin analogs have been released, helping to control blood glucose levels in children and adolescents with diabetes (Table 1, Fig. 1).

It is unclear when the insulin pump was first used in children and adolescents with diabetes in Korea. ${ }^{20)}$ Insulin pumps among Korean patients with diabetes seem to have been used since the late 1970s and the early 1980s. A study of 33 patients admitted to the Department of Pediatrics at Seoul National University Hospital between 1967 and 1983 reported that 2 patients used an insulin pump. ${ }^{15)}$ One experienced pump failure, which was discontinued after 2 years and 6 months of use, and one was in use without any problems.

After the DCCT results were published in 1993, intensive treatment including MDI became the standard for T1D

Table 1. Available insulin preparations in Korea*

\begin{tabular}{|c|c|c|c|c|c|}
\hline Type & Generic name & Brand name & Structural change $(s)^{\dagger}$ & $\begin{array}{l}\text { Year (first launched/ } \\
\text { approved in Korea) }\end{array}$ & Approval age $e^{\ddagger}$ \\
\hline \multirow[t]{2}{*}{ Ultrarapid-acting } & Insulin aspart & Fiasp $^{(}$ & B28; Pro $\rightarrow$ Asp & $2017 / 2018$ & $\geq 2$ Years \\
\hline & Insulin lispro-aabc & Lyumjev ${ }^{\circledR}$ & B28/29; Pro/Lys $\rightarrow$ Lys/Pro & $2020 / 2021$ & $\geq 18$ Years \\
\hline \multirow[t]{3}{*}{ Rapid-acting } & Insulin lispro & Humalog ${ }^{\circledR}$ & B28/29; Pro/Lys $\rightarrow$ Lys/Pro & 1996/1998 & All ages \\
\hline & Insulin aspart & NovoRapid ${ }^{\circledR}$ & B28; Pro $\rightarrow$ Asp & 1999/2002 & $\geq 1$ Year \\
\hline & Insulin glulisine & Apidra ${ }^{\circledR}$ & B29; Lys $\rightarrow$ Glu & $2004 / 2005$ & $\geq 4$ Years \\
\hline Short-acting & Regular insulin & Humulin $R^{\circledR}$ & - & 1982/1987 & All ages \\
\hline Intermediate-acting & $\mathrm{NPH}$ insulin & Humulin $\mathrm{N}^{\circledR}$ & - & 1982/1987 & All ages \\
\hline \multirow[t]{4}{*}{ Long-acting } & Insulin glargine & Lantus $^{\circledR}$ & $\begin{array}{l}\text { A21; Asn } \rightarrow \text { Gly } \\
\text { B30; Added } 2 \text { Arg }\end{array}$ & $2000 / 2004$ & $\geq 2$ Years \\
\hline & Insulin detemir & Levemir $^{\circledR}$ & B30 deleted and C14 fatty acid added & $2004 / 2006$ & $\geq 1$ Year \\
\hline & Insulin glargine U300 & Toujeo $^{\circledR}$ & $\begin{array}{l}\text { A21; Asn } \rightarrow \text { Gly } \\
\text { B30; Added } 2 \text { Arg }\end{array}$ & $2015 / 2015$ & $\geq 6$ Years \\
\hline & Insulin degludec & Tresiba ${ }^{\circledR}$ & B30 deleted and C16 fatty acid added & $2013 / 2014$ & $\geq 1$ Year \\
\hline
\end{tabular}

"Premixed formulations and biosimilar products are not included in this table. ${ }^{\dagger} \mathrm{A}$ and $\mathrm{B}$ denote $\mathrm{A}$ - and B-chain of insulin. Numbers following A or B indicate the number of amino acids in the insulin. ${ }^{\ddagger}$ Approved by Korea Food and Drug Agency as of December 2021. $\mathrm{NPH}$, neutral protamine Hagedorn. 


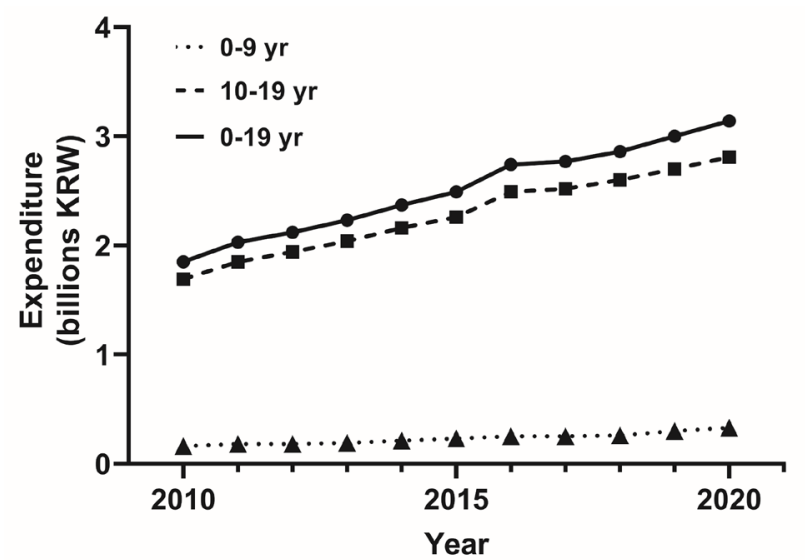

Fig. 2. Temporal trends of expenditure for prescribing insulin under the age of 20 years, 2010-2020. KRW, Korean won.

management. ${ }^{21)}$ Although there was a slight time lag in the introduction of intensive diabetes treatment in Korea, it seems to have followed the trend overseas. According to a recent study, in Korean children and adolescents with T1D between 2010 and 2019, conventional insulin therapy decreased from $33.9 \%$ to $9.0 \%$, and MDI and insulin pumps increased from $63.9 \%$ and $2.1 \%$ to $77.0 \%$ and $14.0 \%$, respectively. ${ }^{22)}$

\section{Trends in insulin prescription for pediatric patients with diabetes}

The change in the total annual insulin prescription cost in Korean children and adolescents with diabetes can be found from the claims data of the National Health Insurance Service (NHIS) (Fig. 2). According to NHIS data, the expenditure for insulin for children and adolescents with diabetes aged 0-19 increased 1.7 times from 1.85 billion Korean won (KRW) in 2010 to 3.14 billion KRW in 2020 . For those aged $0-9$ years, it increased 2.1 times from 0.16 billion KRW in 2010 to 0.33 billion KRW in 2020, and for those aged 10-19 years, it increased by 1.7 times from 1.69 billion KRW in 2010 to 2.81 billion KRW in 2020.

\section{Conclusion}

The discovery of insulin and the application of genetic recombination technology to create insulin analogs have allowed people with diabetes to use more effective insulin regimens for treatment. Before the discovery of insulin, a diagnosis of diabetes was no different from a death sentence, but with the advent of insulin, diabetes has become a manageable disease. In addition, thanks to advances in technology such as genetic recombination technology, continuous glucose monitoring, and insulin pumps, diabetes is becoming a more manageable disease. If new types of smart insulin and more advanced devices are developed in the future, diabetes can become an easier-to-manage disease. If the pathophysiological mechanism of diabetes is further elucidated, a more fundamental treatment can be expected. ${ }^{23)}$

Although the incidence rate of childhood and adolescent diabetes in Korea is lower than that in other countries, it is continuously increasing. Fortunately, the time it takes for diabetes-related drugs or medical devices developed in foreign countries to be introduced into Korea is decreasing over time. Therefore, it is necessary to pay attention to young people with diabetes to effectively manage the illness and achieve normal growth and development, through the application of these medical advances.

\section{Conflicts of Interest}

The authors have no conflicts of interest to declare.

\section{Acknowledgments}

The authors thank the Korean Diabetes Union, Eli Lilly, Novo Nordisk, and Sanofi Aventis for providing the data.

\section{Funding}

This research received no specific grant from any funding agency in the public, commercial, or not-for-profit sectors.

\section{References}

1. Banting FG, Best $\mathrm{CH}$. The internal secretion of the pancreas. J Lab Clin Med 1922;7:251-66.

2. Fralick M, Zinman B. The discovery of insulin in Toronto: beginning a 100 year journey of research and clinical achievement. Diabetologia 2021;64:947-53.

3. Patterson CC, Karuranga S, Salpea P, Saeedi P, Dahlquist G, Soltesz G, et al. Worldwide estimates of incidence, prevalence and mortality of type 1 diabetes in children and adolescents: Results from the International Diabetes Federation Diabetes Atlas, 9th edition. Diabetes Res Clin Pract 2019;157:107842.

4. Shin $\mathrm{CH}$. Epidemiologic characteristics of type 1 diabetes in children aged 14 years or under in Korea, 1985-2000. Korean J Pediatr 2008;51:569-75.

5. Chae HW, Seo GH, Song K, Choi HS, Suh J, Kwon A, et al. Incidence and prevalence of type 1 diabetes mellitus among Korean children and adolescents between 2007 and 2017: an epidemiologic study based on a national database. Diabetes Metab J 2020;44:866-74.

6. The Nobel prize in pharmacy. Chosun Ilbo [Internet]. 1923. [cited 2021 Dec 1]. Available from: https://newslibrary. naver.com/viewer/index.naver?publishDate $=1923$ - 10 29\&officeId=00023\&pageNo=3.

7. Urination in children. Chosun Ilbo [Internet]. 1924. [cited 2021 Dec 1]. Available from: https://newslibrary. naver.com/viewer/index.naver? publishDate $=1924-12$ - 
06\&officeId $=00023 \&$ pageNo=1\#.

8. Chin DS, Lim ES. Diabetes mellitus in infant. J Korean Pediatr Soc 1959;2:131-5.

9. Diagnosis of diabetes mellitus. Dong-A Ilbo [Internet]. 1962. [cited 2021 Dec 1]. Available from: https://newslibrary. naver.com/viewer/index.naver?publishDate $=1962-12$ 18\&officeld $=00020$ \&page $\mathrm{No}=1$.

10. Im NJ, Hong I, Ko KW. A case of juvenile diabetic coma. J Korean Pediatr Soc 1966;9:185-8.

11. Pyun KH, Lee BS, Chung CY. A case of juvenile diabetes mellitus. J Korean Pediatr Soc 1972;15:229-31.

12. Choi JJ, Yun SH. Three cases of juvenile diabetes mellitus occurring in siblings. J Korean Pediatr Soc 1974;17:154-60.

13. Kwon YC, Ahn DH, Ko KW. Remission in juvenile diabetes mellitus. J Korean Pediatr Soc 1971;14:509-13.

14. Suk SB, Ahn HS, Choi Y, Ko KW. Clinical assessment on juvenile diabetes mellitus. J Korean Pediatr Soc 1979;22:223-33.

15. Cheong HI, Kim DG, Choi Y, Ko KW. Clinical observation of juvenile diabetes mellitus. J Korean Pediatr Soc 1983;26:553-63.

16. Moon JS, Won JC, Cho YM. The history of insulin therapy in Korea. Diabetes Metab J 2021;45:623-8.
17. Yoo BS. Recent trends in diabetes treatment. Korean J Med 1959;2:35-8.

18. Moon HR. Juvenile diabetes mellitus. J Korean Med Assoc 1968;11:966-71.

19. Lee TH, Park SC, Kim CH, Shin SM, Lee SJ. Three cases of insulin dependent diabetes mellitus in children. J Korean Pediatr Soc 1983;26:285-9.

20. Moon SJ, Jung I, Park CY. Current advances of artificial pancreas systems: a comprehensive review of the clinical evidence. Diabetes Metab J 2021;45:813-39.

21. The Diabetes Control and Complications Trial Research Group, Nathan DM, Genuth S, Lachin J, Cleary P, et al. The effect of intensive treatment of diabetes on the development and progression of long-term complications in insulindependent diabetes mellitus. N Engl J Med 1993;329:97786.

22. Choe J, Won SH, Choe Y, Park SH, Lee YJ, Lee J, et al. Temporal trends for diabetes management and glycemic control between 2010 and 2019 in Korean children and adolescents with type 1 diabetes. Diabetes Technol Ther 2021 Nov 18. https://doi.org/10.1089/dia.2021.0274. [Epub].

23. Home PD, Mehta R. Insulin therapy development beyond 100 years. Lancet Diabetes Endocrinol 2021;9:695-707. 